\title{
Correction to: Could taxonomic misnaming threaten the ex situ conservation and the usage of plant genetic resources?
}

\author{
Filippo Guzzon $^{1}$ (D) $\cdot$ Nicola M. G. Ardenghi ${ }^{1}$ (D)
}

Published online: 12 February 2018

(C) Springer Science+Business Media B.V., part of Springer Nature 2018

\section{Correction to: Biodivers Conserv (2017) \\ https://doi.org/10.1007/s10531-017-1485-7}

In the original publication of this article, some letters within the caption of Fig. 1 were misplaced. The three illustrated accessions are represented in the composite figure by two images (fruits and foliage), each one identified by means of letters. In the original caption, only one letter, instead of two, is indicated for each accession. The correct version of the caption of Fig. 1 is provided below:

Fig. 1 Propagated Citrullus accessions (see Table 1): a, c, e fruits, scale bar $=5 \mathrm{~cm} ; \mathbf{b}$, d, f foliage. a, b GBR004-83216: C. amarus, c, d RUS001-4679: C. amarus, e, f USA016PI490380: C. mucosospermus. Photos by T. Abeli (a, c, e), V. Ottobrino (b, f), and N. M. G. Ardenghi (d)

The original article can be found online at https://doi.org/10.1007/s10531-017-1485-7.

\section{Filippo Guzzon}

filippo.guzzon01@universitadipavia.it

1 Department of Earth and Environmental Sciences, University of Pavia, I-27100 Pavia, Italy 